\title{
Study of the Relation between Cultural Intelligence and Organizational Commitment among Staff Case Study (Arman Financial Institution)
}

\author{
Ali Dolatshah ${ }^{1}$, Masood Ghorban Hosseini ${ }^{1}, \&$ Masoud Ghorban hosseini ${ }^{1}$ \\ ${ }^{1}$ Department of management, Saveh branch, Islamic Azad university, Saveh, Iran \\ Correspondence: Ali Dolatshah, Department of management, Saveh branch, Islamic Azad university, Saveh, \\ Iran.
}

Received: December 10, 2015

Accepted: January 10, 2016

Online Published: January 13, 2016

doi:10.5539/mas.v10n3p79

URL: http://dx.doi.org/10.5539/mas.v10n3p79

\begin{abstract}
This research intended to study the relation in between cultural intelligence and organizational commitment among the staff of Arman financial institute in Tehran. From all the staff in Arman financial institute by the use of available sampling 234 were selected as the sample of the research. The subjects responded to the cultural intelligence questionnaire (Ank et al., 2004) and organizational commitment (Alen and Maier 1990). The statistical method implemented in this research for data analysis revealed multiple regression and Pearson correlation. The research findings showed that there is a negative and significant relation between cultural intelligence and organizational commitment.
\end{abstract}

Keywords: cultural intelligence, organizational commitment

\section{Introduction}

Not very new challenge of globalization has urged the organizations to enter into a highly dynamic and competitive international environment along with confrontation of different cultures. That's why human management has found out that to work in an international environment requires individuals who well understand cultural differences and bring about high efficiency in multicultural environments and organizations (Tabarsa \& Zamani, 2009). Cultural intelligence is an acquisitive skill which gradually leads to the power of understanding a culture, increasing understanding about it and gradual mental formation to coordinate with that culture so that in confronting other cultures to be able to adapt his behavior to it (ibid). By considering the increasing growth of international interactions and exchanges and heterogeneity of work force, most of the experts of management have directed individual's attention towards identifying and reinforcing capabilities that can lead to efficient presence at highly complex and dynamic environments. Among these capabilities, cultural intelligence is the most significant ability that can be implemented in the face of multicultural situations. Cultural intelligence assists at expeditious and accurate comprehension of different cultural cultures and the apposite behavior to each of them.

One of the responsibilities of every social foundation is to reach the goals whose existence cause creates the foundation. The presence of committed human force to the organization and low burnout in addition to reducing the absence, delay and transference can cause considerable organizational performance and also reaching individual goals. Lack or reduction of high burnout would have negative effects for the organization and the individual that the most evident items are quitting the responsibility, absence, unwillingness to remain in the organization, decline of the customer trust and decline of earnings. Since today organizations are in multicultural environments and each organization is influenced by its environmental conditions cultural intelligence is a factor that can lead to the reduction of burnout and a factor to improve organizational growth and development.

\subsection{Statement of the Problem}

Today because of the increased global communication ${ }^{1}$ and the creation of multicultural companies and cultural diversity $^{2}$ the development of the human knowledge and skill to confront with contradictions and conflicts available in international community are considered as the absolute requirements (Tryandis, 2004). In different culture and even in micro cultures within a national culture there is a large spectrum of feelings and emotions. So that the differences in language, ethnic, political and many other characteristics can emerge as the potential 
sources of contradiction and in case of lack of apposite understanding of them it would pose problems in proper work relations (Tryandis, 2006). Researches show that the differences among the national cultures are on the most significant factors in determining the type of behavior (Green, Hill, \& Barker, 2005).

Beliefs, values, expectations, views, assumptions, are elements of the culture that are not seen but are influential on the behavior of individuals and sometimes lead to work contradictions and diversities. For this purpose cultural adjustment and adaptation Is required. One of the factors which have been highly attended in this respect is called as the moderator factor is cultural intelligence. Cultural intelligence assists at expeditious and accurate comprehension of different cultural cultures and the apposite behavior to each of them. Today's work environment requires individuals who are familiar with different cultures and able to establish apposite relation with people from other cultures. The ability of a person to adapt with the values, traditions, rituals, and different conventions different from what he is accustomed with and working in a workplace with different culture reflects cultural intelligence (Hadizade Moghadam \& Hosseini, 2007). One of the most important means of achieving the goals of any organization is the human force. Managers need to consider the commitment of the work force along with the development of the organizations so that they can handle the problems of the human force in order to reach the goals of the organization in practice. Organizational commitment is an essential factor in fulfilling the benefits of the organization and makes it possible for workers to assist for it rather than acting against it and create problems in the path of it (Dehgani et al., 2012). Organizational commitment refers to the positive and negative view of the staff towards the whole of the organization where they are working. In organizational commitment the person has a strong faithfulness towards the organization and identifies himself by that organization (Steron, 2001). In all definitions of the organizational commitment there are three factors of trust in the goals and values of the organization, strong willingness make attempts for the organization and deep inclination to continue cooperation with the organization. Apposite and accurate interpretation and inference has a significant impact on the organizational commitment of the staff (Mirand et al., 2002) by considering the influences of the organizational commitment may lead to job abandonment, absence, delay, and high organizational commitment can lead to job satisfaction and occupational progress (Mac Orui, 2001) that under different environmental factors and conditions can considerably affect the organizational commitment of the staff towards the organization (Zahedi \& Gajariye, 2011)

By considering the researches which have been carried out about organizational commitment opposite relations have been reported (Gamlik, Siasman, \& Sigri, 2010; Azir, Erigit, \& Arbaharli, 2013; Martinosen, Richardson, \& Burk, 2007; Ashrafi et al., 2010; Golparvar et al., 2011; Bagher poor \& Raees zadeh, 2006; Caraion, 2003). Therefore, this research intends to study the relation in between cultural intelligence and organizational commitment among the staff of Arman financial institute.

\subsection{The Significance of the Study}

Human forces are the most important and valuable factor of organizations and this significance becomes more evident when organizations, their real needs, certain human forces become employed and make efforts in order to maintain and keep and train them. Otherwise this very valuable source would be an extra useless element and the cause of disrupting order (Mirsepas Tabar, 2008). Today organizations are in search of people who are able to act in continual adaptation with persons from other cultural groups and have the ability to behave inter-culturally the workplace of today requires persons who are familiar with different cultures and are able to establish relations with persons from other cultures for this purpose people require cultural intelligence. The ability of a person to adapt with the values, traditions, rituals, and different conventions different from what he is accustomed with and working in a workplace with different culture reflects cultural intelligence (Ghaderi, 2011). Therefore, their familiarity with the human relation knowledge and skill and its application in educational situations is called human skill and in order to enhance organizational commitment and the job burnout is required. If the workers and the staff of an organization have the required skills and abilities without any doubt the organization would have efficiency and practicality. Therefore cultural intelligence enables the staff to establish a better relation and control and mange the cultural diversity. The one who has the cultural intelligence influences the organizational commitment behavior of the persons under the influence and organizational commitment reflects the identity expression. Cultural barriers are felt and know that the same behaviors classify us within the frame work of the organization on the basis of which we can justify different behaviors in the face of various situations and also be able to mange the limits and restriction for the advantage of the organizational goals by apposite moderation of them. No organization will be able to succeed without the organizational commitment of the staff and the efforts of them. Workers with organizational commitment have more order and stability in their job and organizational commitment is a significant occupational view (Jahromi, 2007).

From what explained it was clear that different domains of intelligence and culture especially cultural 
intelligence generate organizational commitment. The subject of this study The subject of this study become considerable since by studying the relation in between cultural intelligence and organizational commitment among the staff of Arman financial institute tries to find out effective and valuable results and also tries to identify meddling factors in this respect by which enhance the work quality level of the organization and enhance the efficiency of the staff. By considering this fact the present research studies the relation in between cultural intelligence and organizational commitment among the staff of Arman financial institute.

\subsection{The Purpose of the Study}

Study the relation in between cultural intelligence and organizational commitment among the staff of Arman financial institute

\subsection{Research Hypothesis}

There is a relation between cultural intelligence and organizational commitment among the staff of Arman financial institute

\section{Theoretical Foundations of Cultural Intelligence}

\subsection{The Concept of Intelligence}

Intelligence because of its different types can be easily estimated or assessed and it's because of it diversity. It needs to be attended that any type of definition about intelligence is limited to a time period and cultural background and according to Mailer intelligence refers to mental calculation and subjective reasoning which is done according to a particular set of principles and parameters (Aghaii et al., 2011). Intelligence refers to the ability to make use of what we have learnt in the face of new confrontation with problems and novice events (Aghaii et al., 2011).

\subsection{Type of Intelligence}

Intelligence in general divides into three type cognitive intelligence, artificial intelligence and social intelligence

1) Cognitive intelligence

According to analytical theoreticians cultural intelligence refers to the ability to make use of the coded events or efficient power and behavior and adaptation with new situations and recognizing environmental qualities and states

2) Artificial intelligence

Artificial intelligence refers to the use of compute to do jobs that if human does them can do them intelligently.

3) Social intelligence

From 1920-1990 the interest in studying social intelligence has experienced fluctuations and various views have emerged in this respect that consider social intelligence in relation with others, inter-personal knowledge the accurate ability to judge about others the disposition of others, efficient social performance, coordination and ability to decode nonverbal codes (Aghaii et al., 2011)

\subsection{The Concept of Culture}

Culture is a term whose application is in two cases: in a filed culture in its broadest meaning refer to the most complex and developed civilization and in another filed it may refer to the concept meant by anthropologists and others who study mankind (Moshbeki, 1998).

\subsection{The Definition and Analysis of Cultural Intelligence}

Cultural intelligence refers to the ability to respond effectively in front of people with diverse cultural background (Aghaii et al., 2011)

\section{Theoretical Foundations of Organizational Commitment}

\subsection{Definitions and Analyses of Organizational Commitment}

Organizational commitment is a significant occupational and professional view. Recent evolutions in the filed of quality and practicality have boosted the importance of organizational commitment in job abandonment and absence and these views are related to the organization and the job which have become more important and organizational commitment can be named as the most significant factor among them. Precise and common definition of this term seems difficult but in all definitions that some are referred below there is a common aspect that commitment is the mental aspect that determines the relation between the person and the organization and holds the decision of whether to stay with the organization or not is covert in it. In Oxfor dictionary the term 
commitment is defined as the requirement which restricts the freedom of action (Rahnamaye Bashti \& Mahmood Zade, 1387)

Organizational commitment refers to a situation in which the staff of the organization considers the organizational goals as their own introduction and wishes to remain in their enrollment (Robinz, 2008).

Maiyer (2002) considers the organizational commitment as a set of internal pressures to do actions. So that the obtained goals and actions are considered as belief and norm in relation with personal responsibility towards the organization to be considered (Eghbali Ghazi, 2010)

\subsection{New Models of Organizational Commitment}

\subsubsection{Multi Dimensional Commitments}

Miyer \& Allen model: they believe that personal commitment connects the person to the organization and therefore, this nexus would probably reduce the chances of job abandonment they have considerably differentiated the following commitments:

Emotional commitment: refers to the emotional dependence of the person to the organization

Continual commitment: about the willingness to stay with the organization because of the expenses of abandoning the organization and the rewards because of staying with the organization.

Normative commitment: feeling of responsibility reflects the need to remain as a member of the organization (Miyer \& Herskowitch, 2001)

PANLI \& GOLD model: they have presented a multilateral frame work they have differentiated three forms of commitment as ethical, prudent and alienation. The definition of ethical commitment is almost the same as the emotional commitment presented by Maiyer and Allen and calculative commitment by Angel and Pery and Mayer and Shorman. The calculative commitment is in line with the obedience rational presented by Erly and Chatman. And finally, their purpose of alienation commitment is almost the same as that of continual commitment presented by Mayer and Aleen (Mayer \& Herskowitch, 2001).

\section{Research Methodology}

The research plan is descriptive and correlation in type and based on predictive researches. Predictive researches lie in between simple correlation and causality researches and this research is of this type.

\section{Research Population}

The research population of the present investigation consists of all the staff in Arman financial institute in Tehran.

\section{Sample, Sampling Method, and the Mass of the Sample}

By the use of available sampling and on the basis of the Morgan table for a population mass of 600 people 234 were selected as the research sample.

\section{Data Collection Method}

By referring to Arman financial institute the staffs were requested to take part in the research. Since the implemented questionnaire in the research estimates the internal characteristics therefore, the secrecy of the data was promised to the participants of the research.

\section{Data Collection Instrument}

\subsection{Cultural Intelligence Questionnaire}

Cultural intelligence scale is a self reporting tool which was created by Ang et al. (2004). This questionnaire consists of 20 questions and four micro scale meta-cognitive, cognitive, motivational and behavioral. The minimum point is 20 and the maximum point is 100 . Cronbach's alpha for meta-cognitive factor $(0 / 76)$, cognitive (0/84), motivational (0/76), behavioral (0/82) is calculated (Ank et al., 2004). In Iran Kazemi (2008) has reported this in reliability research of this questionnaire by the use of Cronbach's alpha as 0/86. Ghadam poor, Mehrdad and Jafari (2011) have reported the calculated reliability by the use of cronbach's alpha as 0.85 .

\subsection{Organizational Commitment}

This questionnaire was prepared by Allen and Mayer in 1990 after repeated revisions and consists of 24 questions that estimates the organizational commitment at three levels namely, emotional commitment (1-8 questions, continual commitment (9-16) and normative commitment (17-24). Rating of this questionnaire is done by the use of 7 degree Lykryt scale (1) I completely disagree, very disagree(2), disagree(3), not disagree not 
agree(4), agree(5), very agree(6). Completely agree (7). Rating the questions, 4, 5, 6, 8, 9, 12, 18, 19, 24. The minimum poit is 24 and the maximum is 168 . The persons on the basis of the obtained scores are placed in three groups of less organizational commitment (less than 56), medium organizational commitment (57-112) and high organizational commitment (more than 113) (Makroy, 2001; Hakt Bisioand Hasdorof, 1994) the reliability indexes of all three types of organizational commitment are reported between $0 / 50$ and $0 / 88$ that show their applicability. In order to obtain this scale correlating the other scales of the organizational commitment has been implemented. The validity of this scale in the researches by Mayer and Allen (1984) and Hakt et al. (1994)

$0 / 60$ up to $0 / 70$ was reported. Th ereliability of this questionnaire in the study carried out by Nahrir and Ebadi (2010) by the use of the retest test 0/94 and in the study by Dehgani et al. (2012) by the use of Cronbach's alpha in all items 0/94 and in emotional domain 0/80 and in continual domain 0/69 and emotional domain 0/74 was reported.

\section{Data Analysis}

Data analysis and study was carried out by the use of SPSS software. In order to analyze the data descriptive and deductive statistics will be implemented. In descriptive statistics central tendencies such as medium and digression tendency indexes such as variance and standard deviation will be implemented and in deductive statistics in order to analyze the data Pearson correlation coefficient will be applied.

\section{Data Analysis}

\subsection{Demographic Data Description}

In this part of the statistical data analysis the distribution of statistical samples will be performed on the basis of the following variables e.g. sex, age, level of education

\section{$10.2 \mathrm{Sex}$}

Table 1. Frequency distribution about sex of the subjects

\begin{tabular}{ccc}
\hline Frequency percentage & Frequency & Sex \\
\hline $64 / 95$ & 152 & man \\
$35 / 05$ & 82 & woman \\
100 & 234 & Total \\
\hline
\end{tabular}

As can be observed in the above table 64/95 percent of the subjects are men and 35/05 percent are women.

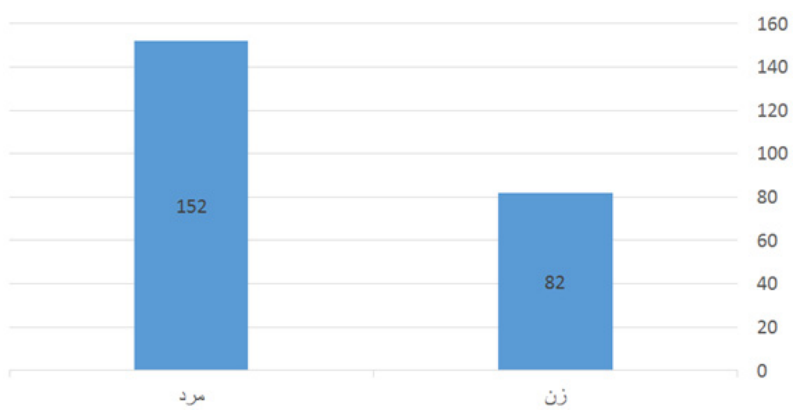

Figure 1. Relative distribution of the subjects' sex

\subsection{Level of Education}

Table 2. Frequency distribution about level of education of the subjects

\begin{tabular}{ccc}
\hline Percent & Frequency & Education level \\
\hline $39 / 75$ & 93 & Bachelor \\
$60 / 25$ & 141 & M.A. \\
100 & 234 & TOTAL \\
\hline
\end{tabular}


On the basis of the above mentioned data most of the staffs have M.A. level of education (i.e. 60/25 percent) while $39 / 75$ percent of the staffs have B.A. degree. The following histogram shows the same results:

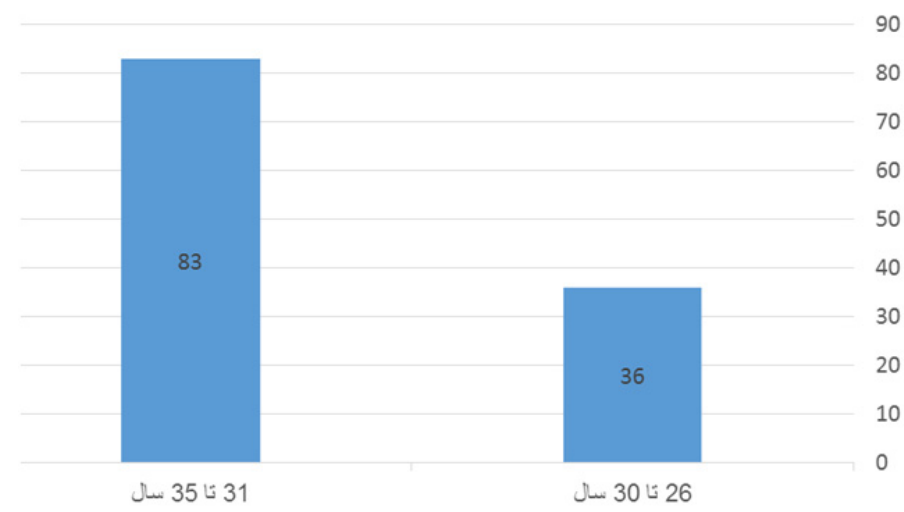

Figure 2. Relative distribution of subjects' level of education

10.4 Age

Table 3. Frequency distribution about level of education of the subjects

\begin{tabular}{ccc}
\hline Frequency percentage & Frequency & Age \\
\hline $15 / 39$ & 36 & year $30-26$ \\
$35 / 47$ & 83 & year $35-31$ \\
$31 / 19$ & 73 & year $40-36$ \\
$17 / 95$ & 42 & year $60-41$ \\
100 & 234 & Total \\
\hline
\end{tabular}

As can be observed in the table and histogram about the age of the staffs the majority of the subjects $(35 / 47$ percent) are in the age group of 31-35. After that the highest frequency belongs to (31/19 percent) staffs that are in age group of 36-40. 17/95 percent of the staff are in the age group of 41-60 and 15/39 percent of them are in the age group of 26-30.

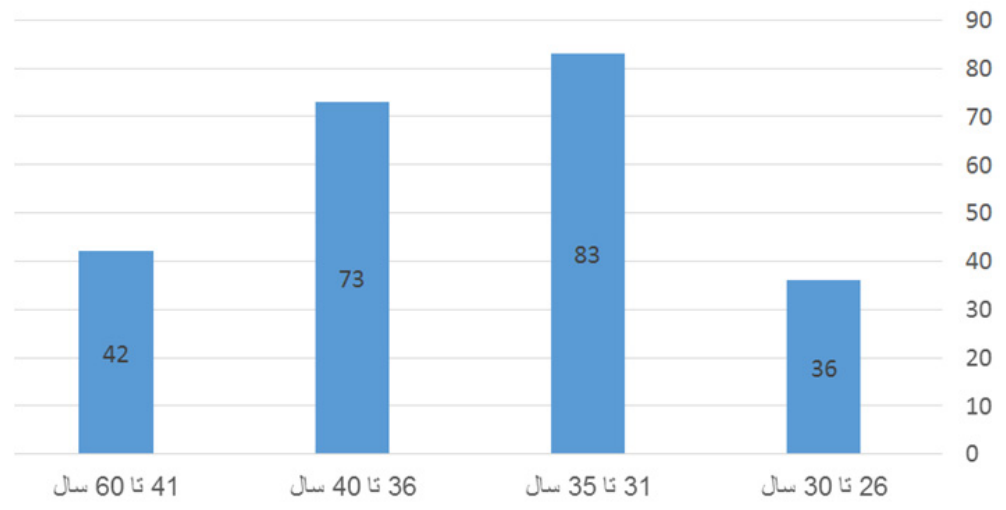

Figure 3. Frequency distribution percentage of the age of the subjects

\section{Research Variables Description}

In this part by the use of frequency tables, diagrams, central tendency indexes and scattering variables are described. 


\subsection{Organizational Commitment}

Table 4

\begin{tabular}{ccccc}
\hline Maximum & Minimum & Standard deviation & Medium & Variable \\
\hline 158 & 35 & $35 / 16$ & $96 / 34$ & Organizational commitment \\
\hline
\end{tabular}

As can be observed in the above table the minimum and maximum point of the subjects in the questionnaire “organizational commitment" respectively equals with 35 and 158. Distribution has the medium of 96/34 and standard deviation is $35 / 16$

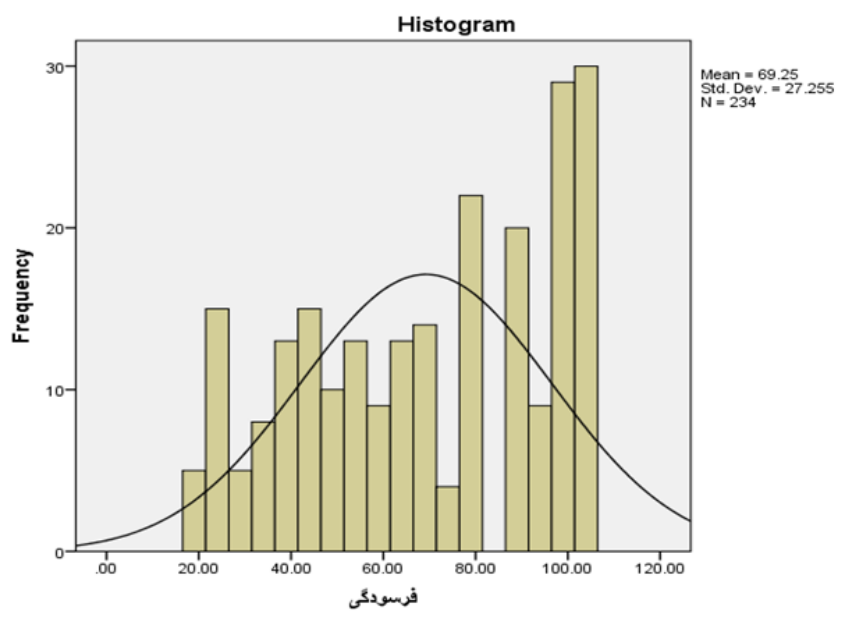

Figure 4. Histogram scale of organizational commitment

\subsection{Cultural Intelligence}

Table 5. Cultural intelligence statistical features

\begin{tabular}{ccccc}
\hline Maximum & Minimum & Standard deviation & Medium & Variable \\
\hline 91 & 29 & $13 / 33$ & $75 / 31$ & Cultural intelligence \\
\hline
\end{tabular}

On the basis of the above table data "cultural intelligence" of the staff equals with $75 / 31$ with standard deviation of $13 / 33$ as calculated.

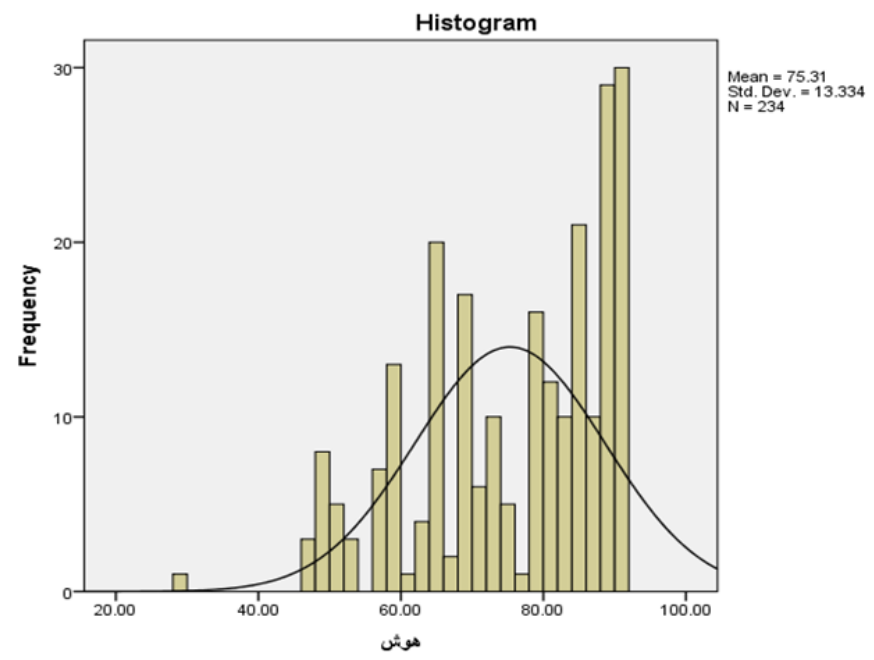

Figure 5. Histogram scale of cultural intelligence 


\section{Normalcy Analysis}

In order to check the normalcy of the data Kolmogorov-Sminrov Test was applied whose summary of findings are presented in the following table

Table 6. Summary table of Sminrov test $(\mathrm{n}=234)$

\begin{tabular}{ccc}
\hline Significance level & Test statistics & Variables \\
\hline $0 / 3$ & $0 / 97$ & organizational commitment \\
$0 / 77$ & $0 / 66$ & Cultural intelligence \\
\hline
\end{tabular}

On the basis of the date presented in the above table the significance level in all variables is larger than 0/05. In other words the data about all three variables follow the normal distribution.

\section{Results Analysis}

In this part on the basis of the research variables the hypothesis is tested by the use of the Pearson Correlation coefficient.

Hypothesis: there is a relation between organizational commitment and cultural intelligence

Table 7. Correlation matrix between organizational commitment and cultural intelligence $(n=234)$

\begin{tabular}{ccc}
\hline 2 & 1 & Variables \\
\hline & - & 1. organizational commitment \\
- & $0 / 375$ & 2. cultural intelligence \\
\hline
\end{tabular}

The data at the above table show that the relations between two variables are at significance level of $(0 / 010 / 01)$ $p=r=0 / 375$. Therefore, we can reject the zero hypothesis at $0 / 01$ level in favor of the research hypothesis and conclude with $99 \%$ certainty that there is a significant relation between organizational commitment and cultural intelligence among the Arman financial institute of Tehran city there is a negative and significant relation. That is by the increase of organizational commitment the cultural intelligenceincreases.

\section{Discussion of the Results}

The present study intended to analyze the relation in between cultural intelligence and burnout among the staff of Arman financial institute in Tehran. In this part the discussion about the findings and the conclusion of the research is presented. First the research findings are presented; then on the basis of the research evidences and related studies the reasons for accepting or rejecting the hypotheses are discussed.

Hypothesis: there is a relation between organizational commitment and cultural intelligence

The results of the correlation show that there is a negative and significant relation between organizational commitment and cultural intelligence. Therefore, the more the organizational commitment the cultural intelligence would increases. Consequently, the research hypothesis is confirmed. This finding is inline with the findings of Zare et al. (2014); Jana Abadi, Karbalee every week, Oktaee (2013), Azarmand, Feizi, Alipoor (2013), KHani et al. (2010), Rahimi nia et al. (2009), Ank et al. (2007) were in line. Zare et al. (2014) showed that there is significant and positive relation between organizational commitment and cultural intelligence. Cultural intelligence poses considerable influence on and it's the most influential direct factor on the rate of the organizational commitment while other factors such as role ambiguity, role pressure, and independence have influences over the organizational commitment. Jena Abadi, Karbalaii Har Hafte, Oktaii (2013) showed that there is a positive and significant relation between Cultural intelligence and organizational commitment related aspects. Among the four domains of Cultural intelligence was the most significant factor on influencing the organizational commitment. Azmand, Feizi and Alipoor (2013) showed that there is a correlation between Cultural intelligence and organizational commitment at Azad University. Khani et al. (2010) have concluded that Cultural intelligence is part of the group efficiency enhancement they showed that Cultural intelligence lead to the enhancement of tolerance, adaptability and better relation between the members. Rahiminia et al. (2009) and Ang et al. (2007) have emphasized the significance of Cultural intelligence they showed that Cultural intelligence and hard attempt for one's organization or the organizational commitment are among the domains of staff performance. 
In various workplaces of the present century it is necessary to manage the stress generated by cultural shock and consequential side effects and disorders created by cultural contradictions in an apposite way. For this purpose efficient adaptation and moderation of the cultures are required. By considering the fact that our country from cultural perspective has a variety of cultures cultural intelligence can be an answer to several concerns in order to improve the work quality in this cultural diversity. Cultural intelligence enables the staff to identify cultural differences by the use of knowledge and awareness and behave properly in different cultures which can lead to the reduction of organizational commitment and increase of the staff efficiency.

\section{References}

Ang, S., Van Dyne, L., Koh, C., Ng, K. Y., Templer, K. J., Tay, C., \& Chandrasekar, N. A. (2007). Cultural intelligence: Its measurement and effects on cultural judgment and decision making, cultural adaptation and task performance. Management and Organization Review, 3(3), 335-371.

Ang. S., Van Dyne, L., Koh, C., \& Ng, K. Y. (2004). The measurement cultural intelligence. Working Paper, presented at the Academy of management symposium on Cultural Intelligence in the 21st century, New Orleans, LA.

Azarvand, J., Feizi, M., \& Alipour, H. (2013). Surveying the Relationship between Cultural Interlligence and organizational Commitment at Islamic Azad University. Arabian Journal of Business and Management Review (OMAN Chapter), 3(3), 78-84.

Barker, C. (2005). Cultural studies: Theory and Practice. Thousand Oaks, CA: sage.

Carayon, P. (2003). Job characteristics and quality of work life in the IT work force. ACM press, New York.

Dehghani, H., Salimi, T., Hooshyar, M., \& Fallahzade, H. (2012). Effect of instruction of reducing work hours on organizational commitment of intensive care units nurses in birjand vali-e-asr hospital. Modern Care, 9(3), 190-8.

Early, P. C., \& Ang, S. (2003). Cultural Intelligence: Individual interactions across cultures. Stanford University Press, Stanford.

Gemlik, N., Sisman, F. A., \& Sigri, U. (2010). The relationship between burnout and organizational commitment among health sector staff in Turkey. Global Strat Manag, 8, 137-49.

Ghaderi, R. (2011). Study of the cultural intelligence and organizational commitment and the efficiency of the educational managers of the west Azerbayjan M. A. educational management Azad. University of Tabriz

Green, L., \& Anna Hill, Y. A. (2005). The Use of Multiple Intelligences to Enhance Team Productivity, Management Decision, 43(3), 349-359.

Hadizade, M. A., \& Hosseinin, A. (2007). Study of the cultura intelligence and group efficiency. Reconstruction center for administrative renewal Shahid Beheshti University of management and Accounting.

Harris, P. R., Moran, R. T., \& Moran, S. V. (2004). Managing cultural differences: Global leadership strategies for the $21^{\text {st }}$ century. Amsterdam: Elsevier/Butterworth-Heinemann.

Jaros, S. (2007). Meyer and Allen Model of organizational commitment:Measurement Issues. Icfai Journal of Organizational Behavior, 5(4), 7-25.

Khaani, A., Abzari, M., \& Etebarian, A. (2010). The Influence Of Cultural Intelligence within Group (in steel company of Mobarake - Esfehan). Journal of Management of Transformations, 4.

Liou, S. R., \& Cheng, C. Y. (2008). Building organizational commitment of Asian nurses in the United States. Nurs Adm., 38(1), 8-10.

Martinussen, M., Richardsen, A., \& Burke, J. (2007). Job Demands, Job Resours and Burniut among Poblice Officers. Journal of Criminal Justice, 35, 239-249.

Maslach, C., \& Jackson, S. E. (1981). The measurement of experienced burnout. Journal of occupational behavior, 19, 99-113.

Maslach, C., Schaufcli, W. B., \& Leiter, M. P. (2001). Job Burnout. Annual Review of Psychology, 52, 397-422.

Mc Elroy, J. C. (2001). Managing workplace commitment by putting people first. Human Resource Management Review, 11, 327-35.

Meyer, J. P., \& Lierscovitch, L. (2001). Commitment in the work place toward.

Meyer, J. P., Stanley, D. J., Herscovitch, L., \& Topolnytsky, L. (2002). Affective, continuauce and normative 
commitment to the organization:A meta-analyss of antecedents,correlates and consequence. Vocat Behav., 61(1), 20-52.

Moshbeki, A., \& Tizroo, A. (2009). Motivational and cultural intelligence. International leaders management research essay, 3, 73-53

Peierson, B. (2004). Cultural in teuigence: Aguid to Working with people from other cultures. Yurnouth M. E., intercultural press.

Rabinz, S. (2008). Organizational behavior management. Pub cultural research office.

Rahimi, N. F. et al. (2009). In Investigation of the Influence of Culture Intelligence on task performance of Management. Farda Scientific Journal, 22.

Raieszadeh, S., \& Bagherpour, M. (2006). Study the relationship between organizational commitment and job burnout among staff Contacts PA. M.Sc., Thesis, University of Behbahan.

Rhanamaye, P., \& Fereidoon, M. Z. (2008). Human force development. Tehran industrial management pub.

Steron, H. (2001). Management in Education. 5(17).

Triandis, H. C. (2004). The many dimensions of culture. Academy of Management Executive, 18 (1).

Zahedi, S. M., \& Ghajarieh, F. (2011). Relationship between organizational commitments and nurses intention to remain at health centers affiliated to army of the islamic republic of Iran. Iran J Nurs Res., 24(73), 19-26.

Zare, R., Hosseinin, R., Yazdan, P., \& Mohsen, Ch. M. (2014). Study of the cultural intelligence and organizational commitment of the Fars province education and traing ministry. 2013-2014 the first national psychological and training sciences Marvdasht, Andishe sazan Mobtaker Javan.

\section{Copyrights}

Copyright for this article is retained by the author(s), with first publication rights granted to the journal.

This is an open-access article distributed under the terms and conditions of the Creative Commons Attribution license (http://creativecommons.org/licenses/by/3.0/). 